\title{
Los comunes digitales y la esfera pública digital: sobre cómo hacer avanzar la democracia digital en la actualidad $^{1}$
}

\section{Christian Fuchs ${ }^{2}$}

\begin{abstract}
El presente artículo es una traducción ${ }^{3}$ de Fuchs, C. (2021). The Digital Commons and the Digital Public Sphere: How to Advance Digital Democracy Today. Westminster Papers in Communication and Culture, 16(1), 9-26. DOI: https://doi.org/10.16997/wpcc.917

Cómo citar: Fuchs, C. (2021). Los comunes digitales y la esfera pública digital: sobre cómo hacer avanzar la democracia digital en la actualidad. (Traducción de Ana Marotias, Guillermo Quiña, Emilio Cafassi y Agostina Dolcemáscolo). Revista Hipertextos, 9(16), 13-34. https://doi.org/10.24215/23143924e038
\end{abstract}

Resumen. Este trabajo se pregunta: ¿cuáles son los potenciales democráticos de los comunes digitales y de la esfera pública digital? Primero, se identifican diez problemas del capitalismo digital. Segundo, se aborda la noción de esfera pública digital. Tercero, se delinea el concepto de los comunes digitales. Cuarto, se elaboran algunas conclusiones y presentan diez sugerencias para el avance de la democracia digital.

Este artículo contribuye a la teorización y el análisis del capitalismo digital, plataformas de Internet, la esfera pública digital, los comunes digitales, la democracia digital, plataformas de Internet públicas, plataformas de Internet de la sociedad civil/comunitarias, plataformas cooperativas, acceso abierto, acceso abierto corporativo/capitalista, y acceso abierto diamante. Este trabajo también esboza diez problemas del capitalismo digital, así como diez principios del progresismo digital, una política que hace avanzar la esfera pública y los comunes, y, por consiguiente, la democracia (digital) en la sociedad.

Existen dimensiones naturales, económicas, políticas, y culturales de los comunes y de los comunes digitales. El capitalismo, la esfera pública, y la sociedad civil de los medios/de los medios comunitarios/de las cooperativas son tres formas de organización y gobernanza de Internet y de los medios digitales/las tecnologías digitales. El capitalismo coloniza y mercantiliza los comunes (digitales) y la esfera pública (digital). Modelos alternativos pueden ser localizados por fuera del capitalismo, en el área de la esfera pública y de la sociedad civil, así como en la interacción entre estas.

Palabras clave: comunes digitales, esfera pública digital, capitalismo digital, medios de comunicación públicos, plataformas de Internet como servicio público, plataformas cooperativas, cooperativismo de plataformas.

${ }^{1}$ [Nota de lxs traductores] Algunas aclaraciones preliminares: 1. la noción de commons ha sido traducida aquí como comunes y como bienes comunes; 2. los fragmentos citados por el autor han sido traducidos directamente del inglés sin consultar, en caso de que hubiera, otras ediciones en castellano.

${ }^{2}$ Christian Fuchs es profesor en estudios de medios y comunicación. Es el director del Communication and Media Research Institute (www.camri.ac.uk), editor de la revista tripleC: Communication, Capitalism \& Critique (www.triple-c.at), y autor de aproximadamente 400 trabajos sobre teoría crítica de la comunicación y los medios digitales en la sociedad. Contacto: @fuchschristian; http:/ / fuchsc.net.

3 Traducción realizada por parte del equipo editorial de Hipertextos: Ana Marotias, Guillermo Quiña, Emilio Cafassi y Agostina Dolcemáscolo. 
Sumario. 1. Introducción. 2. Capitalismo digital. 2.1 La esfera pública digital. 2.2 ¿Qué son los medios lentos? 2.3 Los bienes comunes digitales. 3. Conclusión: promoviendo la democracia digital.

\section{The Digital Commons and the Digital Public Sphere: How to Advance Digital Democracy Today}

Abstract. This paper asks: what are the democratic potentials of the digital commons and the digital public sphere? First, the article identifies ten problems of digital capitalism. Second, it engages with the notion of the digital public sphere. Third, it outlines the concept of the digital commons. Fourth, some conclusions are drawn and ten suggestions for advancing digital democracy are presented.

This article contributes to theorising and the analysis of digital capitalism, Internet platforms, the digital public sphere, the digital commons, digital democracy, public service Internet platforms, civil society/community Internet platforms, platform cooperatives, open access, corporate/capitalist open access, and diamond open access. This work also outlines ten problems of digital capitalism as well as ten principles of digital progressivism, a politics that advances the public sphere and the commons and thereby (digital) democracy in society.

There are natural, economic, political, and cultural dimensions of the commons and the digital commons. Capitalism, public service, and civil society media/community media/cooperatives are three forms of organisation and governing the Internet and digital media/technologies. Capitalism colonises and commodifies the (digital) commons and the (digital) public sphere. Alternative models are located outside of capitalism in the realms of the public sphere and civil society as well as their interactions.

Keywords: digital commons, digital public sphere, digital capitalism, public service media, public service Internet platforms, platform co-operatives, platform cooperativism.

\section{O Digital Commons e a Esfera Pública Digital: Como Avançar na Democracia Digital Hoje}

Resumo. Este artigo pergunta: quais são os potenciais democráticos dos bens comuns digitais e da esfera pública digital? Primeiro, o artigo identifica dez problemas do capitalismo digital. Em segundo lugar, ele se envolve com a noção de esfera pública digital. Terceiro, esboça o conceito do bens comuns digitais (digital commons) Em quarto lugar, algumas conclusões são tiradas e dez sugestões para o avanço da democracia digital são apresentadas.

Este artigo contribui para a teorização e análise do capitalismo digital, plataformas de Internet, esfera pública digital, bens comuns digitais, democracia digital, plataformas de Internet de serviço público, plataformas de Internet de sociedade civil / comunidade, cooperativas de plataforma, acesso aberto, acesso aberto corporativo / capitalista, e acesso aberto de diamante. Este trabalho também descreve dez problemas do capitalismo digital, bem como dez princípios do progressismo digital, uma política que avança a esfera pública e os bens comuns e, portanto, a democracia (digital) na sociedade.

Existem dimensões naturais, econômicas, políticas e culturais dos bens comuns e dos bens comuns digitais. Capitalismo, serviço público e mídia da sociedade civil / mídia comunitária / cooperativas são três formas de organização e governança da Internet e das mídias / tecnologias digitais. O capitalismo coloniza e mercantiliza os bens comuns (digitais) e a esfera pública (digital). Os modelos alternativos estão localizados fora do capitalismo, nos domínios da esfera pública e da sociedade civil, bem como em suas interações.

Palavras-chave: bens comuns digitais, esfera pública digital, capitalismo digital, mídia de serviço público, plataformas de serviço público de Internet, cooperativas de plataforma, cooperativismo de plataforma. 


\section{Introducción}

En los últimos 15 años, las nociones de big data y social media se han vuelto parte de la cotidianeidad. Asociado a esto, hemos experimentado el ascenso de plataformas como Google, YouTube, Facebook, Amazon, Twitter, Apple, Baidu, Instagram, WhatsApp, WeChat, Alibaba, Spotify, y Netflix. Estas plataformas recolectan grandes cantidades de datos personales de usuarios y proveen servicios como motores de búsqueda, plataformas de video, redes sociales, microblogs de compras online, plataformas para compartir fotografías, aplicaciones de mensajería, o streaming de música y películas.

Este trabajo se pregunta: ¿cuáles son los potenciales democráticos de los comunes digitales y de la esfera pública digital? Primero, se identifican diez problemas del capitalismo digital. Segundo, se aborda la noción de esfera pública digital. Tercero, se delinea el concepto de los comunes digitales. Cuarto, se elaboran algunas conclusiones y presentan diez sugerencias para la promoción de la democracia digital.

\section{Capitalismo digital}

El capitalismo es un tipo de sociedad basada en la lógica de acumulación de poder (Fuchs, 2020a). El capital monetario es una forma particular e importante del poder que es acumulado en la sociedad capitalista. Pero la lógica de acumulación también da forma a la política y la cultura. La política, en la sociedad capitalista, es la esfera de la acumulación relativa al poder de decisión. La cultura es, en la sociedad capitalista, la esfera de la acumulación de la reputación. La inequidad e injusticias son consecuencia de la lógica de acumulación: la economía capitalista es modelada por la explotación del trabajo y la distribución asimétrica de la riqueza; el sistema político del capitalismo es modelado por la dominación y la influencia asimétrica; el sistema cultural del capitalismo es modelado por la ideología, la falta de reconocimiento y de respeto.

El capitalismo digital no es una nueva fase del desarrollo capitalista, sino más bien una dimensión de la organización del capitalismo que es moldeada por la mediación digital. En el capitalismo digital, los procesos sociales tales como la acumulación de poder, la acumulación capitalista, las luchas de clase, las disputas políticas, la hegemonía, la ideología, la mercantilización, o la globalización, se encuentran mediadas por las tecnologías digitales, la información digital, y la comunicación digital. Las corporaciones digitales y de comunicación transnacionales juegan un rol importante en el capitalismo digital.

Veintiun de las cien corporaciones transnacionales más grandes del mundo operan en la industria de lo digital, los medios y la comunicación (Tabla 1). Subsectores de esta industria, incluyen, por ejemplo, la publicidad, redes de transmisión, almacenamiento en la nube, redes de comunicación/digitales, juegos digitales, hardware digital, servicios y plataformas digitales, cultura del ocio y del entretenimiento en vivo, shopping online, streaming online, o software. El total de las ganancias de las 21 corporaciones dominantes de la comunicación/lo digital/los medios alcanzó, en el año 2019, 2.5 billones de dólares, que compusieron el 3\% del producto bruto interno global de ese año ${ }^{4}$. El hecho de que 21 compañías controlen el 3\% de la riqueza financiera global producida durante un año, da cuenta del gran poder de las compañías capitalistas, incluyendo a las corporaciones de lo digital y la comunicación.

4 PBI global de 2019: US\$ 33.426 billones. Fuente: https://data.worldbank.org/indicator/NY.GDP.MKTP. CD (ultimo acceso: 7/10/ 2020). 
Tabla $\mathbf{n}^{\mathbf{0}}$ 1: Las corporaciones dominantes transnacionales de la comunicación y lo digital

\begin{tabular}{|c|c|c|c|c|c|}
\hline Ranking & Compañía & $\begin{array}{l}\text { País de la } \\
\text { sede } \\
\text { central }\end{array}$ & Mercancías & $\begin{array}{l}\text { Ingresos } \\
\text { anuales } \\
\text { (US\$ mil } \\
\text { millones) }\end{array}$ & $\begin{array}{l}\text { Ganancias } \\
\text { anuales } \\
\text { (US\$ mil } \\
\text { millones) }\end{array}$ \\
\hline 9 & Apple & EEUU & $\begin{array}{l}\text { Hardware digital, } \\
\text { software, servicios } \\
\text { digitales, streaming } \\
\text { online, almacenamiento } \\
\text { en la nube }\end{array}$ & 267.7 & 57.2 \\
\hline 11 & AT\&T & EEUU & $\begin{array}{l}\text { Redes de } \\
\text { comunicación/digitales, } \\
\text { redes de transmisión }\end{array}$ & 179.2 & 14.4 \\
\hline 13 & Alphabet & EEUU & $\begin{array}{l}\text { Publicidad digital, } \\
\text { servicios digitales y } \\
\text { software (por ejemplo: } \\
\text { Google, YouTube, } \\
\text { Sistema operativo } \\
\text { Android, Chrome) }\end{array}$ & 166.3 & 34.5 \\
\hline 13 & Microsoft & EEUU & $\begin{array}{l}\text { Software (por ejemplo: } \\
\text { Windows, Office, } \\
\text { Skype), hardware (Xbox) }\end{array}$ & 138.6 & 46.3 \\
\hline 16 & $\begin{array}{l}\text { Samsung } \\
\text { Electronics }\end{array}$ & $\begin{array}{l}\text { Corea del } \\
\text { Sur }\end{array}$ & Hardware digital & 197.6 & 18.4 \\
\hline 20 & $\begin{array}{l}\text { Verizon } \\
\text { Communications }\end{array}$ & EEUU & $\begin{array}{l}\text { Redes de } \\
\text { comunicación/digitales }\end{array}$ & 131.4 & 18.4 \\
\hline 22 & Amazon & EEUU & $\begin{array}{l}\text { Plataformas de compra } \\
\text { online, streaming online } \\
\text { de contenido digital, } \\
\text { almacenamiento en la } \\
\text { nube }\end{array}$ & 296.3 & 10.6 \\
\hline 27 & Comcast & EEUU & $\begin{array}{l}\text { Redes de } \\
\text { comunicación/digitales, } \\
\text { redes de transmisión }\end{array}$ & 108.7 & 11.7 \\
\hline 28 & China Mobile & China & $\begin{array}{l}\text { Redes de } \\
\text { comunicación/digitales }\end{array}$ & 108.1 & 15.5 \\
\hline 31 & Alibaba & China & $\begin{array}{l}\text { Plataformas de compra } \\
\text { online, pago online, } \\
\text { streaming de } \\
\text { entretenimiento online. }\end{array}$ & 70.6 & 24.7 \\
\hline 36 & Walt Disney & EEUU & $\begin{array}{l}\text { Contenido de } \\
\text { entretenimiento, redes } \\
\text { de transmisión, } \\
\text { plataformas de } \\
\text { entretenimiento digital y } \\
\text { de streaming, parques de } \\
\text { diversión, } \\
\text { marchandising }\end{array}$ & 74.8 & 10.4 \\
\hline 38 & Intel & EEUU & Hardware digital & 75.7 & 22.7 \\
\hline 39 & Facebook & EEUU & $\begin{array}{l}\text { Publicidad digital, } \\
\text { servicios digitales } \\
\text { (Facebook, Instagram, } \\
\text { WhatsApp) }\end{array}$ & 73.4 & 21 \\
\hline 43 & $\begin{array}{l}\text { Nippon } \\
\text { Telegraph \& Tel }\end{array}$ & Japón & $\begin{array}{l}\text { Redes de } \\
\text { comunicación/digitales }\end{array}$ & 109.6 & 7.9 \\
\hline
\end{tabular}




\begin{tabular}{|c|c|c|c|c|c|}
\hline 50 & Tencent & China & $\begin{array}{l}\text { Publicidad digital, } \\
\text { servicios digitales (QQ, } \\
\text { WeChat), juegos } \\
\text { digitales, streaming de } \\
\text { música y video }\end{array}$ & 54.6 & 13.5 \\
\hline 51 & IBM & EEUU & $\begin{array}{l}\text { Hardware, software, } \\
\text { computación en la nube }\end{array}$ & 76.5 & 9.0 \\
\hline 58 & Sony & Japón & $\begin{array}{l}\text { Hardware, juegos de } \\
\text { video, contenido de } \\
\text { entretenimiento }\end{array}$ & 79.2 & 6 \\
\hline 66 & SoftBank & Japón & $\begin{array}{l}\text { Redes de } \\
\text { comunicación/digitales, } \\
\text { hardware digital }\end{array}$ & 87.4 & 2.9 \\
\hline 69 & $\begin{array}{l}\text { Deutsche } \\
\text { Telekom }\end{array}$ & Alemania & $\begin{array}{l}\text { Redes de } \\
\text { comunicación/digitales }\end{array}$ & 90.1 & 4.3 \\
\hline 82 & Cisco Systems & EEUU & $\begin{array}{l}\text { Hardware digital, } \\
\text { software }\end{array}$ & 51.6 & 11.1 \\
\hline \multirow[t]{2}{*}{94} & Oracle & EEUU & $\begin{array}{l}\text { Hardware digital, } \\
\text { software }\end{array}$ & 39.8 & 10.8 \\
\hline & & & Total: & $2,477.2$ & 367.0 \\
\hline
\end{tabular}

Fuente: Lista Forbes 2000 (año 2000). Disponible en: www.forbes.com/global2000 (último acceso $7 / 10 / 2020)$

El capitalismo digital ha sido moldeado por diez grandes problemas sociales (véase Fuchs, 2021, especialmente el capítulo 14):

1. El capital comunicacional y digital explota la comunicación y el trabajo digital y ha dado lugar a la tendencia a la monopolización capitalista en la industria de la comunicación en general y la digital en particular.

2. La cultura dominante de Internet está conformada por una cultura digital competitiva e individualista centrada en el yo y enfocada en la acumulación y distribución asimétrica de la atención, la influencia, la reputación, la visibilidad y la voz.

3. Las empresas de comunicacionales y digitales y los aparatos estatales han creado un complejo industrial de vigilancia.

4. Los medios de comunicación capitalistas son medios antisociales que han contribuido al avance de los potenciales antidemocráticos, el autoritarismo digital, el racismo digital, el nacionalismo digital y el fascismo digital.

5. En la política algorítmica, los algoritmos crean el contenido y la atención online, y así se vuelve difícil para los humanos discernir qué actividades online son humanas y cuáles son máquinas.

6. En el mundo online, existen esferas públicas digitales fragmentadas en las que encontramos ciertas burbujas que logran filtrar lo expuesto.

7. La industria de la cultura digital ha creado la ideología digital, ideologías sobre lo digital e ideología difundida a través de las redes digitales. La publicidad digital y los contenidos sensacionalistas dominan el mundo online. Muchas plataformas digitales son periódicos digitales. 
8. El capitalismo de los influencers domina las redes sociales y ha creado una atención, reputación y visibilidad asimétricas en Internet, así como una cultura ideológica dominada por las compras y la publicidad. La publicidad se oculta cada vez más y se presenta como contenido habitual ("branded content"). "El capitalismo de los influencers no es un tipo de capitalismo, sino una ideología que afirma que siendo activo en plataformas de redes sociales como Instagram, Snapchat y YouTube hay grandes oportunidades para hacerse rico y famoso. El capitalismo de los influencers es el sueño, la fantasía y el deseo de los usuarios de convertirse en celebridades que acumulan una gran cantidad de relaciones sociales, dinero, influencia, likes, comentarios positivos, etc. El capitalismo de los influencers es la manifestación online de la afirmación ideológica del sueño americano de que en el capitalismo todo el mundo tiene las mismas oportunidades de hacer carrera, desde un lavaplatos hasta un multimillonario, teniendo una buena idea y creyendo en sí mismo" (Fuchs, 2021: 175).

9. La gran cantidad de flujos de información online procesados a gran velocidad ha dado lugar a la aceleración digital. Falta tiempo y espacio para el debate político sostenido.

10. En las redes sociales, es frecuente encontrar noticias falsas y políticas post-factuales que niegan los hechos y se dejan llevar por la emocionalización, el sensacionalismo y la ideología.

Las consecuencias combinadas que estos diez desarrollos traen consigo implican una amenaza a la democracia y hemos experimentado el surgimiento de un capitalismo autoritario donde demagogos de extrema derecha dominan la política (Fuchs, 2018a, 2020b). La digitalización no es la causa de estos desarrollos, sino que ha influido el antagonismo entre el capitalismo neoliberal y el crecimiento de las desigualdades sociales. La mercantilización, privatización, comercialización y la individualización ha vuelto (casi) todo contra los valores cívicos y las libertades políticas del liberalismo, dando lugar a nuevas fuerzas nacionalistas, racistas, xenófobas, autoritarias y fascistas en la sociedad.

Entonces, surgen las preguntas: ¿cuáles son las alternativas al capitalismo digital y el autoritarismo digital? ¿La esfera pública digital y los bienes comunes digitales pueden ser esas alternativas?

\subsection{La esfera pública digital}

La comunicación política es un aspecto importante e indispensable del sistema político en todos los modelos de democracia. En términos generales, se puede decir que el público es un mecanismo central del sistema político. Por "público" entendemos generalmente los bienes y espacios que son "abiertos a todos" (Habermas, 1989: 1). Se habla, por ejemplo, de educación pública, edificación pública, parques públicos, plazas públicas, asambleas públicas, manifestaciones públicas, opinión pública, medios públicos, etc. Los bienes e instalaciones públicas no están reservados para una camarilla o un club de privilegiados, sino que están destinados al público en general, es decir, a todos los miembros de la sociedad.

La esfera pública es una esfera de comunicación política pública que media entre los otros subsistemas de la sociedad, a saber, la economía, la política, la cultura y la vida privada. El tipo ideal de esfera pública es un ámbito de la sociedad que organiza la "publicidad crítica" (Habermas, 1989: 237) y el "debate público crítico" (Habermas, 1989: 52). La esfera pública mediatiza la comunicación política. Es un espacio mediatizador de comunicación política en el que los ciudadanos se encuentran, se informan sobre la vida en sociedad y se comunican políticamente. La esfera pública es un espacio donde se forman las opiniones políticas. La 
comunicación pública es un aspecto importante de la existencia de los seres humanos como seres sociales y de la sociedad. En la sociedad moderna, el sistema de medios es la forma organizada más importante de comunicación pública. En el sistema de medios, los actores de los medios producen información pública. Hay una serie de críticas al concepto de esfera pública de Habermas, principalmente desde el campo de los estudios posmodernos. Quien suscribe ha criticado en otros lugares el rechazo hacia este autor y a su concepto de esfera pública y argumenta que la noción de Habermas es útil y puede actualizarse a la era digital (ver Fuchs, 2014b).

La esfera pública digital no es una esfera separada de la sociedad, sino una dimensión y aspecto de la esfera pública en sociedades donde la información y la comunicación digitales son predominantes. La esfera pública digital significa la publicación de información, la publicidad crítica y el debate público crítico mediado por las tecnologías de la información y la comunicación digitales. No toda la información y comunicación a través de Internet, teléfonos móviles y tabletas forma parte de la esfera pública digital. Cuando los procesos de mercantilización y de acumulación capitalista (la lógica de acumulación económica), la dominación (la lógica de acumulación política) y la ideología (la lógica de acumulación política) dan forma a las prácticas digitales, esta última no forma una esfera pública. La esfera pública digital ha sido entonces, como sostiene Habermas (1989), colonizada y feudalizada. Entonces podemos hablar de una esfera digital alienada y una comunicación alienada pero no de una esfera pública digital. Los diez procesos descritos en la sección anterior son manifestaciones de alienación digital, colonización digital y feudalización digital.

Los medios de comunicación pública son medios de comunicación que operan en la esfera pública y a través de ella. El experto en comunicación Slavko Splichal da una definición precisa de los medios de servicio público:

En términos normativos, los medios de comunicación pública deben ser un servicio del público, por el público, y para el público. Es un servicio del público porque lo financia y debe ser propiedad de él. Debería ser un servicio del público, no solo financiado y controlado, sino también producido por él. Debe ser un servicio para el público, pero también para el gobierno y demás poderes que actúan en la esfera pública. En resumen, los medios de comunicación pública deberían convertirse en 'la piedra angular de la democracia' (2007: 255).

Los medios de producción de los medios de comunicación pública son de propiedad pública. La producción y circulación de los contenidos se basa en una lógica no lucrativa y en la misión de tales medios como servicio público. El acceso es universal, ya que todos los ciudadanos tienen fácil acceso a los contenidos y tecnologías de los medios de comunicación públicos. En términos políticos, los medios de comunicación públicos ofrecen un contenido diverso e inclusivo que promueve el entendimiento y el discurso político. En términos culturales, ofrecen contenidos educativos que contribuyen al desarrollo cultural de los individuos y la sociedad. Los medios de comunicación públicos tienen una misión especial, legalmente definida, que consiste en producir y proporcionar contenidos y servicios que contribuyan a promover la democracia, la educación y la cultura. En ciertos debates, los medios de comunicación públicos, como la BBC, a menudo se presentan incorrectamente como medios de comunicación estatales o medios controlados por el Estado. Los verdaderos medios de comunicación públicos están legalmente habilitados por el 
Estado (financiación, y misión como servicio público), pero no están controlados por el Estado. Los medios de comunicación públicos son organizaciones de medios de comunicación independientes habilitados por las leyes del Estado.

Debido a las cualidades especiales de los medios de comunicación públicos, estos pueden también hacer una contribución democrática y educativa especialmente valiosa a la esfera pública democrática online y a la democracia digital, si se les proporcionan los medios materiales y legales necesarios para ello.

La vida en las sociedades modernas se ha acelerado cada vez más, lo que incluye la aceleración de la economía, de la toma de decisiones políticas, los estilos de vida y las experiencias (Fuchs, 2014a; Rosa, 2013). La lógica de la acumulación capitalista es el motor de la aceleración (véase Fuchs, 2014a). Como consecuencia, la velocidad de las relaciones sociales se ha incrementado, especialmente desde el auge del capitalismo neoliberal. En el ámbito de los medios de comunicación, la aceleración de los flujos de información ha contribuido a un aspecto de la construcción sensacionalista de los medios y la comunicación que, a su vez, resulta un aspecto de la comercialización, la monopolización y la mercantilización de los medios de comunicación.

Los medios de comunicación predominantes son espectáculos de alta velocidad, superficiales y caracterizados por la falta de tiempo para el debate. Erosionan de este modo la esfera pública y la cultura de la discusión política. No dejan tiempo ni espacio a los ciudadanos para comprender la complejidad de la sociedad y desarrollar argumentos. Lo que necesitamos hoy es la desmercantilización y la desaceleración de los medios de comunicación. Necesitamos medios de comunicación lentos (ver Fuchs, 2021; Köhler, David y Blumtritt, 2010; Rauch, 2018).

\section{2. ¿Qué son los medios lentos?}

Los medios de comunicación lentos reducen la velocidad de la información, las noticias y la comunicación política mediante la reducción de la cantidad de flujos de información y comunicación. Los usuarios interactúan más profundamente entre sí y con el contenido. Los medios lentos no distraen a los usuarios con anuncios, no se basan en la vigilancia del usuario y no se comprometen a generar ganancias. No se trata simplemente de una forma diferente de consumo de medios, sino una forma alternativa de organizar y hacer medios, un espacio de reflexión y debate político racional (Fuchs, 2021: 363).

Los medios lentos y la comunicación política lenta no son nuevos. Club 2 en Austria y después Dark en el Reino Unido son ejemplos prototípicos. Los periodistas Kuno Knöbl y Franz Kreuzer diseñaron el concepto de Club 2 para la Austrian Broadcasting Corporation (ORF). Era un programa televisivo de debate que se emitía habitualmente los martes y jueves. El primer programa se emitió el 5 de octubre de 1976 y el último el 28 de febrero de 1995. Mil cuatrocientos programas fueron transmitidos por ORF (Der Standard, 2001). Club 2 tuvo una nueva edición que se transmitió de 2007 a 2012. Sin embargo, utilizaron un concepto diferente que ya no adhería a los principios originales.

En el Reino Unido, la productora de medios Open Media creó un formato similar basado en el Club 2 bajo el nombre After Dark que se transmitía una vez a la semana en Channel 4 entre 1987 y 1991 y ocasionalmente a partir de entonces. En 2003, After Dark se mostró durante un breve período en la BBC.

El productor de After Dark, Sebastian Cody, describe el concepto de Club 2 / After Dark del siguiente modo: 
el número de participantes en estos debates íntimos (siempre realizados en ambiente agradable y sin público) nunca fue menos de cuatro, nunca más de ocho (como, por cierto, ocurre en una terapia de grupo); la discusión debe ser presentada y orientada por un no experto, cuya función rota, eliminando así el culto a la personalidad que afecta a los presentadores; los participantes deben ser una selección diversa, todos directamente involucrados en el tema en discusión de esa semana; y, lo más importante, el programa debía transmitirse en vivo y tener un final abierto. La conversación termina cuando los invitados deciden, no cuando el personal de la televisión los obliga a detenerse. (Cody, 2008).

El concepto de Club 2 suena bastante inusual para muchas personas hoy en día, ya que estamos tan acostumbrados a formatos de corta duración, alta velocidad y falta de tiempo en los medios y en nuestra vida diaria. Las discusiones abiertas, sin censura, controvertidas y en vivo que atraen al espectador y al público son diferentes de los medios acelerados en términos de espacio y tiempo: el Club 2 era un espacio público donde los invitados se reunían y discutían entre ellos en una atmósfera que ofrecía tiempo ilimitado, el cual era experimentado públicamente y durante el cual se discutían temas de importancia social. Club 2 era un espacio público democrático en la televisión pública.

El espacio y el tiempo son dos dimensiones importantes de la política económica pública. Sin embargo, un espacio social que ofrezca suficiente tiempo para la discusión no es garantía de compromiso ni de una discusión crítica y dialéctica que trascienda la unidimensionalidad, que penetre en las profundidades de un tema y destaque las similitudes y diferencias de diferentes posiciones. El espacio y el tiempo deben organizarse y gestionarse de manera inteligente, de modo que participen las personas adecuadas, el ambiente sea apropiado, se realicen preguntas de discusión acertadas y se garantice que todos los participantes expresen su opinión, se escuchen unos a otros y que la discusión pueda desarrollarse sin inconvenientes. Un espacio ilimitado, dialécticamente controvertido e intelectualmente desafiante, y una organización inteligente son tres aspectos importantes de la publicidad. Estas son condiciones previas para los medios lentos, los medios no comerciales, los medios descolonizados y los medios de interés público.

Necesitamos medios lentos. Online y offline. Desaceleremos los medios y creemos medios lentos 2.0. ¿Es posible hoy una nueva versión del Club 2 (Club 2.0) como parte de la esfera pública digital?

El Club 2.0 es un ejemplo de una plataforma de Internet de servicio público que ayuda a promover la comunicación democrática y la esfera pública digital. En el Club 2.0, los principios tradicionales del Club 2 son practicados y actualizados (ver Figura 1). Se trata de un polémico debate en vivo en estudio, sin límite de tiempo. Se emite por televisión y también en una plataforma de vídeo de servicio público, una versión de servicio público de YouTube. Las redes sociales permiten contenido generado por el usuario y debate online. Una versión actualizada de Club 2 debería hacer uso de las posibilidades de los medios digitales: en Club 2.0, los usuarios pueden abrir temas de discusión y discutir en formato de texto y video, basados en el formato del canal de YouTube de servicio público que acompaña a la emisión televisiva del Club 2.0. En ciertos momentos del debate televisivo, las discusiones en video generadas por un usuario son seleccionadas y se transmiten como parte de la discusión televisiva para que formen parte del debate de estudio. 
Figura $\mathbf{n}^{\mathbf{0}}$ 1: Club 2.0.

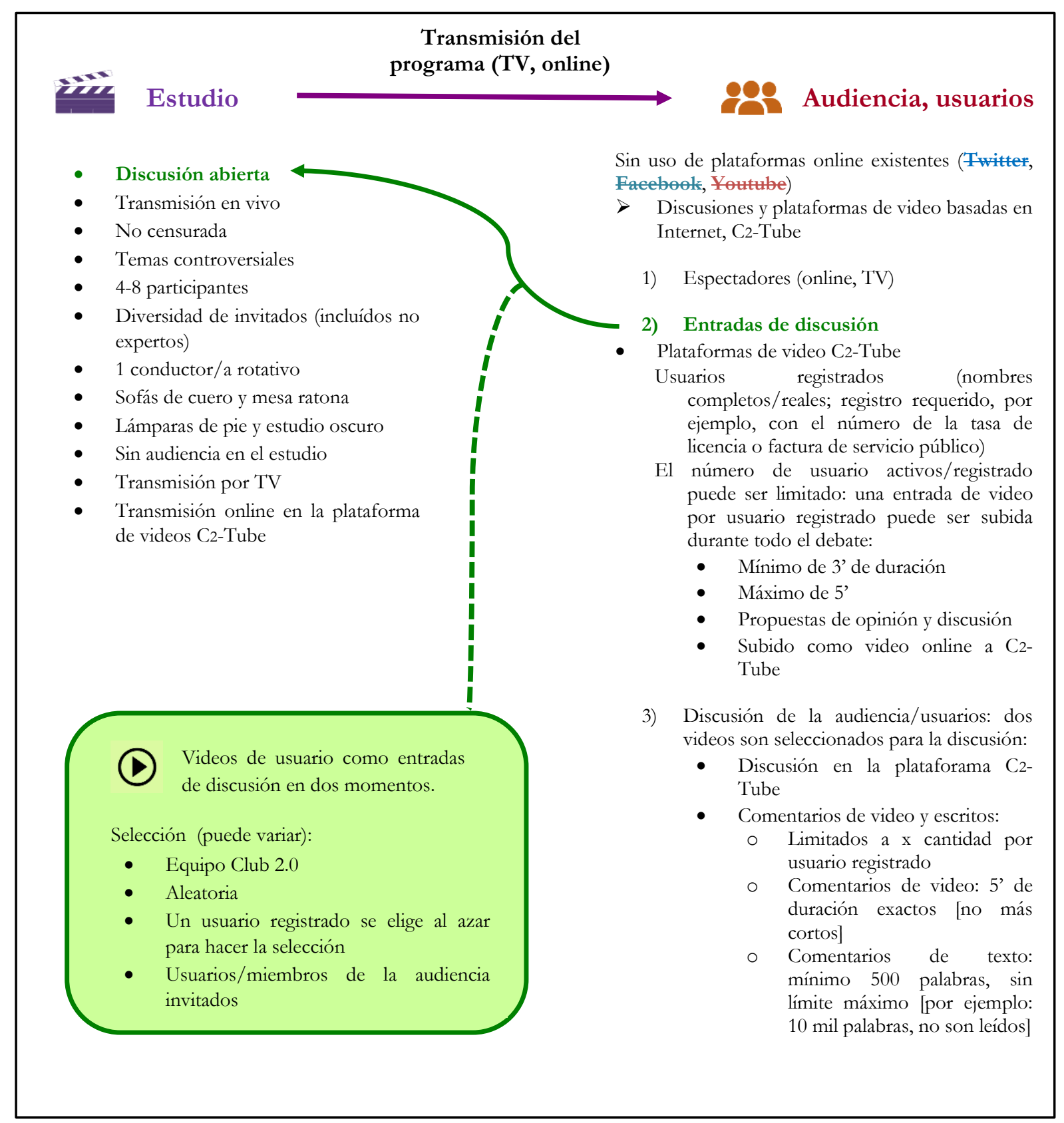

Fuente: Publicado como CC en Fuchs (2018b: 74).

El Club 2.0 es una expresión de la democracia digital y la esfera pública digital. Manifiesta una combinación de elementos de democracia deliberativa y participativa, crea "diseños institucionales de la democracia moderna" que se basan en el "principio de reciprocidad" (Held, 2006: 233). Permite "encuentros sociales que tienen en cuenta el punto de vista de los demás, el punto de vista moral" (Held, 2006: 233), pone "mayor énfasis en esos entornos y los procedimientos de formación de preferencias y aprendizaje dentro de la política y la sociedad civil "(Held, 2006: 233) y permite "dar razones, explicaciones y rendir cuentas de las decisiones públicas" (Held, 2006: 237). Destaca la dimensión comunicativa de la democracia y que "la 
reflexión crítica debe vincularse con el debate público y la política deliberativa" (Held, 2006: 241). El Club 2.0 es un mecanismo comunicativo que permite una mayor reflexión, explicación y debate en política y, por lo tanto, puede fortalecer los aspectos deliberativos de la democracia. La democracia participativa destaca "la participación directa de los ciudadanos en la regulación de instituciones clave de la sociedad, incluido el lugar de trabajo y la comunidad local" (Held, 2006: 215).

El Club 2.0 aumenta la participación de los ciudadanos en la cultura y en el debate político. Es un aspecto participativo de la cultura y la política. Ofrece espacio y tiempo para la comunicación política controvertida y permite a los ciudadanos participar en la discusión, tanto colectiva como individualmente, a través de videos y comentarios. El Club 2.0 reúne el aspecto comunicativo de la democracia deliberativa y la idea participativa de la democracia de base. La esfera pública digital y las plataformas de Internet como servicio público son fenómenos sociales que se oponen y desafían al capitalismo digital y a la Internet capitalista.

\section{3 Los bienes comunes digitales}

Elinor Ostrom, ganadora del Premio Nobel de Ciencias Económicas en 2009, define a los bienes comunes con una teoría de los bienes económicos que se basa en la exclusión y la capacidad de sustracción. Para Ostrom, los recursos comunes tienen una alta capacidad de sustracción y una baja exclusividad (Hess y Ostrom, 2007: 9). Un ejemplo de esto es una biblioteca con accesibilidad abierta: tiene una barrera de entrada baja (baja exclusividad) y una alta sustracción (se vuelve inutilizable si demasiadas personas la usan a la vez). En contraste, la autora argumenta que una puesta de sol es un bien público porque no tiene rivalidad en el consumo (baja sustracción) y es difícil excluir a alguien del sol y de ver la puesta de sol (baja exclusividad).

El problema con el concepto de Ostrom es que descuida la economía política, es decir, el concepto de propiedad común. Ostrom despolitiza así el concepto de los bienes comunes. Yochai Benkler argumenta que, por influencia de las obras de Ostrom, "se desarrolló una literatura más estrechamente definida" (Benkler, 2006: 480). Benkler aboga por "una teoría completamente diferente de los bienes comunes" (Benkler, 2013: 1510). Define los bienes comunes de la siguiente manera:

Los bienes comunes son una forma alternativa de espacio institucional, donde las personas pueden actuar libres de las limitaciones particulares requeridas para los mercados y tener cierto grado de confianza en que los recursos que necesitan para sus planes estarán a su disposición. Tanto la libertad de acción como la seguridad de la disponibilidad de recursos se logran en esquemas muy diferentes a los de los mercados basados en la propiedad (Benkler, 2006: 144)

Para Benkler, los bienes comunes son recursos no comerciales y sin fines de lucro que están disponibles para todos (para otra definición, véase Bauwens, Kostakis y Pazaitis, 2019: 3). Slavoj Žižek (2010, 212-13) identifica tres formas de los bienes comunes:

- los bienes comunes culturales: lengua, medios de comunicación, educación, infraestructuras;

- $\quad$ los bienes comunes de naturaleza externa: el medio ambiente natural;

- los bienes comunes de naturaleza interna: el ser humano. 
Michael Hardt y Antonio Negri (2017: 166) identifican dos formas básicas de los bienes comunes, es decir, los bienes comunes sociales y los naturales. Subdividen estos dos tipos en cinco formas de los comunes:

- $\quad$ los bienes comunes naturales: los ecosistemas, la tierra;

- $\quad$ los bienes comunes sociales 1: códigos, ideas, imágenes, productos culturales;

- $\quad$ los bienes comunes sociales 2: productos físicos comúnmente producidos por el trabajo cooperativo;

- $\quad$ los bienes comunes sociales 3: espacios rurales y metropolitanos donde el ser humano se comunica, coopera e interactúa culturalmente;

- $\quad$ los bienes comunes sociales 4: instituciones que brindan atención médica, educación, vivienda y bienestar para todos

Karl Marx destacó que hay recursos en la sociedad que se producen de manera colectiva y cooperativa. Argumenta que el trabajo universal crea bienes comunes que son "proveídos en parte por la cooperación de los hombres que viven en la actualidad, pero también fueron en parte construidos por trabajos anteriores" e implican la "cooperación directa de los individuos" (Marx, 1894: 199). Los bienes comunes son recursos de propiedad colectiva y producidos de manera cooperativa. Los bienes naturales comunes son recursos producidos por la naturaleza que son necesarios para la supervivencia de todos los seres humanos. Esto incluye la tierra y el universo como el hábitat natural de los humanos. La naturaleza se produce y se reproduce a sí misma constantemente. Es un sistema autoorganizado. La naturaleza como tal es, por su propia naturaleza, un bien común, ya que cuando se produce a sí misma está al alcance de todos.

Sin embargo, históricamente el capital expropió y encerró partes de la naturaleza para que se convirtieran en propiedad privada. En la Edad Media, los humanos usaban la tierra, los bosques, los campos, los prados, etc. como bienes comunes. La formación del capitalismo implicó lo que Marx denominó acumulación originaria (1867: parte 8), la transformación violenta de los humanos en trabajadores asalariados. Una medida fue el cercamiento legal de los bienes comunes naturales para que la tierra se convirtiera en propiedad privada. Los campesinos fueron expulsados de la tierra y en adelante tuvieron que vivir como trabajadores asalariados.

Los bienes producidos socialmente son comunes cuando son de propiedad colectiva y producidos de manera cooperativa. Hay un importante principio moral-político subyacente en el pensamiento y la visión política de Marx y Engels: quienes producen los bienes deben poseerlos colectivamente. Para Marx y Engels, la característica central de una sociedad comunista es que hay una propiedad común de los medios de producción por parte de los trabajadores:

En este sentido, la teoría comunista puede resumirse en una sola frase: abolición de la propiedad privada. [...] Cuando, por lo tanto, el capital se convierte en propiedad común, en propiedad de todos los miembros de la sociedad, la propiedad personal no es por lo tanto transformada en propiedad social. Es sólo el carácter social de la propiedad lo que es cambiado. Pierde su carácter de clase (Marx y Engels, 1848: 498, 499).

Según Marx y Engels, los bienes comunes no son bienes que asuman ciertas características de la teoría de los bienes económicos. Más bien, cualquier bien puede transformarse en propiedad colectiva. Argumentan que los medios de producción deben ser bienes comunes. Una característica clave del capitalismo neoliberal ha sido la transformación de los bienes comunes en 
propiedad privada y mercancías como parte del proceso que David Harvey (2005: 165-72) llamó mercantilización de todo.

La mercantilización es un proceso económico que destruye el fundamento material de los bienes comunes. Convierte algo que es disponible y accesible a todos y, por lo tanto, beneficia a todos, en una propiedad privada controlada y negociada en los mercados. Utman (2020) señala que, en el ámbito de la comunicación, el capitalismo neoliberal ha resultado en la expropiación de la voz como recurso y práctica común y, por lo tanto, ha socavado la democracia. Basada en un modelo de sociedad, la Tabla 2 identifica cuatro tipos y dimensiones de los bienes comunes.

Tabla $\mathbf{n}^{\mathbf{0}} 2$ : cuatro tipos y dimensiones de los bienes comunes

\begin{tabular}{ll} 
Esfera de la sociedad & $\begin{array}{l}\text { Tipos de los comunes } \\
\text { naturaleza }\end{array}$ \\
$\begin{array}{ll}\text { Comunes naturales: sustentabilidad } \\
\text { ambiental }\end{array}$ \\
\hline política & Comunes económicos: socialismo \\
& $\begin{array}{l}\text { Comunes políticos: democracia } \\
\text { participative }\end{array}$ \\
\hline cultura & $\begin{array}{l}\text { Comunes culturales: cultura de la } \\
\text { amistad }\end{array}$ \\
\hline
\end{tabular}

\section{Significado de los comunes} digitales

Acceso común a los recursos naturales para todos, uso común de recursos naturales de maneras medioambientalmente sustentables Propiedad común de los medios de producción

Personas que son afectadas por determinados fenómenos pueden tomar decisiones colectivas sobre estos temas, derechos políticas básicos garantizados para todos, así como el respeto mutuo.

Todas las personas son respetadas y son capaces de entenderse y vivir juntas a través de prácticas comunes en la cotidianeidad, de manera tal que se vuelva posible la amistad y la diversidad de estilos de vida, identidades y comunidades.

Fuente: [no se indica en el original]

Euler (2018) subraya que existe una dimensión estructural y práctica de lo común. "La comunalización puede considerarse como la práctica social que hace a lo común lo que es. [...] Lo común es la forma social de la materia (tangible y/o intangible) que está determinada por la comunalización" (Euler, 2018: 12). En el capitalismo, los bienes comunes solo pueden existir como semillas de una sociedad común (Euler, 2018: 12). Antonis Broumas (2020,11-14) señala a los comunes como una dialéctica de recursos y comunidad. Dado que los bienes comunes no son solo recursos, sino recursos comunes integrados en las prácticas de comunión de las comunidades (Papadimitropoulos, 2020: capítulo 1), hay un "elemento comunicativo distintivo" en esa comunión (Utman, 2020: 158).

Los bienes comunes digitales son recursos digitales que comúnmente son controlados por seres humanos. La Tabla 3 presenta cuatro tipos y dimensiones de los bienes comunes digitales. 
Tabla $\mathbf{n}^{\mathbf{0}}$ 3: Cuatro tipos y dimensiones de los comunes digitales

\begin{tabular}{|c|c|c|}
\hline Esfera de la & Tipos de los comunes digitales & Significado de los comunes digitales \\
\hline naturaleza & $\begin{array}{l}\text { Comunes digitales naturales: } \\
\text { sustantibilidad ambiental digital }\end{array}$ & $\begin{array}{l}\text { Control común de las minas donde se } \\
\text { extraen los recursos naturales que forman } \\
\text { las bases físicas de las tecnologías digitales, } \\
\text { impactos ambientales sustentables de las } \\
\text { tecnologías digitales que garanticen la } \\
\text { supervivencia común de la naturaleza, los } \\
\text { seres humanos y la sociedad (por ejemplo, } \\
\text { computación verde) }\end{array}$ \\
\hline economía & $\begin{array}{l}\text { Comunes digitales económicos: } \\
\text { socialismo digital }\end{array}$ & $\begin{array}{l}\text { Propiedad común de los medios de } \\
\text { producción digitales }\end{array}$ \\
\hline política & $\begin{array}{l}\text { Comunes digitales políticos: democracia } \\
\text { digital participativa }\end{array}$ & $\begin{array}{l}\text { Gobernanza colectiva de las decisiones } \\
\text { acerca del uso de los recursos digitales }\end{array}$ \\
\hline cultura & $\begin{array}{l}\text { Comunes digitales culturales: amistades } \\
\text { digitales }\end{array}$ & $\begin{array}{l}\text { Unidad en la diversidad y reconocimiento } \\
\text { común y respeto de todos en las } \\
\text { comunidades digitalmente mediatizadas de } \\
\text { modo tal que se habiliten amistades }\end{array}$ \\
\hline
\end{tabular}

Fuente: Desarrollo basado en Fuchs (2021, tabla 8.2).

A nivel de infraestructuras digitales, las redes comunitarias que funcionan como cooperativas son ejemplos de proyectos de bienes comunes digitales. A nivel de software y contenidos digitales, el software libre y las licencias Creative Commons no comerciales son ejemplos de proyectos de bienes comunes digitales. El software libre y de código abierto (FLOSS) tiene potencial postcapitalista, pero también han sido subsumido de varias formas al capital (ver Berlinguer, 2020; Birkinbina, 2020). A nivel de plataformas digitales, las plataformas cooperativas son ejemplos de proyectos de bienes comunes digitales. Se trata de plataformas de Internet sin fines de lucro que son de propiedad colectiva y gobernadas por los trabajadores digitales que producen los recursos que sustentan estas plataformas (ver Sandoval, 2020; Scholz, 2016, 2017; Scholz y Schneider, 2016). Ejemplos de plataformas cooperativas son la plataforma de música Resonate (una alternativa a Spotify, https://resonate.is), Fairbnb (una alternativa a Airbnb, https://fairbnb.coop), Taxiapp (una alternativa a Uber), la plataforma de demografía y video Stocksy (una alternativa a Shutterstock e iStockPhoto, www.stocksy.com), o la plataforma de colaboración Loomio (www.loomio.org).

Las cooperativas en el ámbito de la economía digital promueven los bienes comunes económicos y los bienes comunes políticos porque son organizaciones sin fines de lucro que se gobiernan y controlan colectivamente. No son el único proyecto de bienes comunes digitales. Por ejemplo, los proyectos de Internet como servicio público promueven los bienes comunes económicos, ya que son propiedad del público, y los bienes comunes políticos y culturales, ya que se basan en las atribuciones de servicio público. Los proyectos de bienes comunes digitales no avanzan automáticamente en todos los niveles de los comunes. Por ejemplo, las redes comunitarias no reducen necesariamente los residuos electrónicos y el consumo de energía 
(sustentabilidad medioambiental). Algunos aspectos de los bienes comunes están cubiertos por definición por los proyectos de bienes comunes digitales, mientras que otros solo se logran mediante un compromiso activo más allá de la base de proyectos particulares.

La publicación de acceso abierto ha emergido como respuesta a las prácticas monopólicas de los editores capitalistas. Las revistas de acceso abierto y las casas editoras muy frecuentemente utilizan licencias de tipo Creative Commons, lo cual convierte al contenido de los trabajos publicados en un común digital, en el sentido de que constituye un bien común al que cualquier persona puede acceder y no es propiedad exclusiva de nadie, sino una forma de conocimiento que es provista a la humanidad como recurso gratuito. Hacia el 28 de febrero de 2021, 15989 revistas de acceso abierto se encontraban listadas en DOAJ (Directorio de Revistas de Acceso Abierto, por sus siglas en inglés).

Pero el acceso abierto no es de manera automática un verdadero común digital que manifiesta las cuatro formas de los comunes digitales identificadas en la Tabla 3. Las editoriales capitalistas de acceso abierto han subsumido el acceso abierto al capital (véase Knoche, 2020). Estas son editoriales de acceso abierto lucrativas que acumulan capital. La estrategia de acumulación capitalista que ellos emplean más frecuentemente es el cobro de altas tasas a los autores que no sólo cubren los costos de producción sino también ganancias que son apropiadas de modo privado. En el acceso abierto capitalista, el contenido digital es des-mercantilizado, es decir, los artículos y los libros son publicados como Creative Commons, pero los principios de acumulación de capital, mercantilización, valorización y rentabilidad no son abandonados, sino transformados. La oportunidad de ser publicado es mercantilizada, mientras el contenido publicado es un común. Los comunes digitales son de esta manera subsumidos bajo y colonizados por el capital digital. El acceso abierto capitalista es un capitalismo digital de los comunes. "En el Modelo de Acceso Abierto Corporativo, las compañías, organizaciones o redes publican material online en versión digital, lo hacen liberando del pago a sus lectores, pero derivan ganancias monetarias con estrategias tales como cobrarle a los autores o vender espacio publicitario" (Fuchs y Sandoval, 2013: 438).

Las licencias de los comunes deberían enfocarse sobre el avance de proyectos sin fines de lucro, que son semillas del postcapitalismo. Las licencias de los comunes tales como las Creative Commons no son automáticamente críticas del capitalismo; algunas de ellas son compatibles con, subsumidas bajo y sostenedoras del capitalismo. En contraste, los accesos abiertos diamante son verdaderos proyectos de comunes digitales que tienen un carácter no capitalista. El acceso abierto diamante es:

una forma de publicación académica sin fines de lucro que hace del conocimiento académico un bien común, reclama el carácter común del sistema académico y conlleva la posibilidad de promover la seguridad laboral al crear empleos de (un) servicio público de publicaciones. (...) En el Modelo de Acceso Abierto Diamante, las asociaciones, redes, organizaciones no comerciales o sin fines de lucro publican material que es puesto disponible online en formato digital, no cobra cargos a lectores ni autores y no admite ser reutilizado con sentido lucrativo ni comercial. (Fuchs y Sandoval, 2013: 428, 438). 
El Acceso Abierto Radical es una red de proyectos de acceso abierto diamante que,

promueve una visión progresiva para la publicación abierta en las humanidades y las ciencias sociales. (...) Nosotros también compartimos una voluntad de subordinar algunas de nuestras prácticas de comunicación académica más establecidas a la crítica creativa, junto con las instituciones que las sostienen (la universidad, la biblioteca, la casa editorial, y otras). El colectivo también ofrece una "alternativa" radical a las versiones conservadoras de acceso abierto que están actualmente siendo propuestas por imprentas con orientación comercial, patrocinadores y funcionarios de gobierno. (...) Al exhibir la amplia variedad de modelos no comerciales, sin fines de lucro y/o basados en los comunes para la creación y diseminación del conocimiento académico que se encuentran actualmente disponibles, nosotros procuramos ayudar a generar y sostener la diversidad en la ecología de la publicación. (Radical Open Access, s/f)

La pregunta que resta ser respondida es si y cómo los proyectos de Internet como servicio público y los comunes digitales pueden contribuir a promover la democracia digital. La conclusión se enfoca en este asunto.

\section{Conclusión: promoviendo la democracia digital}

La esfera pública digital es una dimensión de la esfera pública, donde el conocimiento publicado asume formatos digitales e informa un debate público crítico. Para Habermas, la esfera pública tiene un carácter democrático, no capitalista y no ideológico. Por lo tanto, no todo conocimiento digital y no toda comunicación digital es parte de la esfera pública. Los medios del servicio público son medios que son públicamente poseídos por organizaciones sin fines de lucro que no son controlados sino habilitados por el estado y operan un servicio público básico para proporcionar contenido y servicios que promueven la comunicación, la educación y la cultura democráticas. Las plataformas de Internet de servicio público son plataformas de Internet que pertenecen, son operadas y mantenidas por medios del servicio público. Al igual que estos últimos, las plataformas de Internet de servicio público son medios de la esfera pública, que se encuentran en y operan a través de ella. Los proyectos digitales de la sociedad civil, como las plataformas de acceso abierto diamante y las cooperativas, son proyectos digitales sin fines de lucro de propiedad colectiva y gobernados por los trabajadores que producen los recursos que sostienen estos proyectos. Las plataformas de Internet de servicio público y las plataformas digitales de la sociedad civil o medios comunitarios forman tanto parte de la esfera pública como de la esfera pública digital. Su principal diferencia es que la organización que opera, controla y posee la plataforma es en el primer caso una organización de medios de comunicación de servicio público y un grupo o comunidad de la sociedad civil, en el segundo. Las plataformas de Internet de servicio público operan más cerca del estado que las plataformas cooperativas y otros proyectos digitales de la sociedad civil. Sin embargo, las plataformas de Internet de servicio público no están controladas, sino antes bien habilitadas por el estado.

La Tabla 4 describe algunos fundamentos de tres economías políticas de plataformas digitales. Las plataformas de Internet de servicio público y las plataformas de Internet de la sociedad civil son los dos tipos de plataformas digitales que operan sobre principios no capitalistas y, por lo tanto, son negativos para la economía política del capitalismo digital. Operan en la esfera pública digital. En contraste, las plataformas digitales capitalistas colonizan, 
feudalizan, alienan y destruyen la esfera pública digital. Las plataformas de Internet de servicio público y las plataformas de Internet de la sociedad civil son excelentes cimientos para promover los bienes comunes digitales, es decir, la sustentabilidad ambiental digital (los comunes digitales naturales), el socialismo digital (comunes digitales económicos), la democracia digital participativa (los comunes digitales políticos) y las amistades digitales (los comunes digitales culturales). La creación de tales plataformas digitales no capitalistas no es una condición suficiente para el avance de los comunes digitales, pero sí una buena base que tiene una mayor probabilidad y oportunidad de promover la democracia digital, la igualdad digital y la justicia digital que el capitalismo digital y las plataformas digitales capitalistas. Se necesita un esfuerzo humano consciente, una lucha social y bases materiales para avanzar en todas las dimensiones de los comunes digitales. Por ejemplo, una plataforma digital puede ser gobernada y poseída democráticamente (en términos políticos y económicos) pero promover la basura electrónica y el cambio climático. Por lo tanto, las organizaciones y comunidades que operan estas plataformas deberían apoyar la creación de computación verde no capitalista.

Tabla $\mathbf{n}^{\mathbf{0}}$ 4: Tres economías políticas de las plataformas digitales

\section{Dimensión Plataformas capitalistas de Internet}

economía

Capital digital, propiedad privada de plataformas digitales que acumulan capital

política

Gobernanza por propietarios privados, accionistas y gerentes

$\begin{array}{ll}\text { cultura } & \text { Contenido digital } \\ \text { públicamente disponible } \\ \text { que es proclive a ideología y } \\ \text { valores capitalistas }\end{array}$

Plataformas de Internet de servicio público

Organización de servicio público

Plataformas de

Internet de la

sociedad civil, medios comunitarios

digitales

Propiedad comunitaria, propiedad de la organización de la sociedad civil, cooperativas

Gobernanza por un directorio
democráticamente legitimado

Contenido digital y servicios digitales que concretan los propósitos de servicio público de comunicación, educación, cultura y participación democráticas
Gobernanza por la comunidad de miembros/ trabajadores/ usuarios

Contenido digital y
servicios que sostienen
la creatividad de los
usuarios, periodismo
ciudadano y
participación digital

Fuente: Desarrollo basado en Fuchs (2021, tabla 8.2).

La colonización política es el principal peligro que enfrentan los proyectos de servicios públicos de Internet. Los medios de servicio público pierden su independencia y carácter crítico cuando los gobiernos pueden influir directamente en la designación de directorios, la contratación y despido de trabajadores y el contenido producido. Tales medios son medios controlados por el estado, no medios de servicio público. Al igual que los medios tradicionales de servicio público, los proyectos de servicios públicos de Internet se enfrentan al peligro de la 
colonización política. La marginación y la neoliberalización son los dos principales peligros que enfrentan las plataformas de Internet de la sociedad civil, así como las plataformas cooperativas. La historia de los medios alternativos y comunitarios es una historia de precariedad de recursos y trabajo voluntario, precario y autoexplotación. Precariedad de recursos y trabajo precario son los dos peligros político-económicos gemelos que enfrentan los proyectos comunitarios alternativos. Además, la cultura digital está fuertemente moldeada por una cultura de individualismo y emprendedorismo neoliberal. Los dos principales peligros que enfrentan las cooperativas de plataforma son que (1) siguen siendo justas y democráticas pero pequeñas, precarias y sin importancia, lo cual puede llevar a su ruina, y (2) se convierten en proyectos capitalistas.

Nick Srnicek (2017: 127) argumenta que "todos los problemas tradicionales de las cooperativas (por ejemplo, la necesidad de autoexplotación bajo relaciones sociales capitalistas) son aún peores por la naturaleza monopolística de las plataformas, el predominio de los efectos de red y los vastos recursos detrás de estas empresas" (Srnicek, 2017: 127). Marisol Sandoval (2020) analiza cómo las plataformas cooperativas han empleado el lenguaje neoliberal del emprendimiento ("creadores", “emprendedor", “innovación”, “inversiones", “accionistas", "ganancias", “acciones”, etc.) y cómo este enfoque ha promovido el individualismo y socavado el potencial de las cooperativas para políticas radicales. "Pero la propiedad colectiva y la gobernanza democrática no protegen automáticamente a las cooperativas de las dinámicas del emprendedorismo" (Sandoval, 2020: 811).

El principal peligro que enfrentan las plataformas de Internet de servicio público y las plataformas cooperativas es ser paralizadas o destruidas por las contradicciones derivadas de la colonización económica, política o ideológica, de manera tal que no puedan desafiar y oponerse al poder de las plataformas de Internet capitalistas. Por lo tanto, promover una Internet alternativa solo puede tener éxito si es parte de un movimiento político y una campaña más amplios para fortalecer la esfera pública y los bienes comunes en la sociedad. El avance de la esfera pública digital, los comunes digitales y la democracia digital requiere una política progresista que aborde temas como los siguientes:

1. Tecno-realismo: La política digital progresista debe evitar tanto el tecno-optimismo como el tecno-pesimismo y promover proyectos y plataformas realistas que sean posibles, factibles, desafíen y se opongan, y apunten más allá del capitalismo digital.

2. El avance de la democracia digital, la esfera pública digital y los comunes digitales deben ser parte integrante de los movimientos, partidos y partidos de movimientos que hacen campaña por el fortalecimiento de la democracia, la esfera pública y los comunes en general. El avance del control común de los medios de comunicación requiere el avance del bien común y los comunes en la sociedad en general.

3. Promover la democracia digital, la esfera pública digital y los comunes digitales no es una cuestión técnica, sino una cuestión de lograr buenas condiciones laborales para los trabajadores digitales y de la comunicación (y los trabajadores en general) y una buena vida para todos en la sociedad digital.

4. La política digital progresista necesita defender la ruptura de los monopolios capitalistas en el sector de las comunicaciones, los medios y el digital en particular, y en la economía en general.

5. La política digital progresista debe exigir y promover la eliminación de los paraísos fiscales corporativos, la elusión fiscal corporativa y los impuestos corporativos bajos. Debería hacer campaña e implementar tasas impositivas corporativas más altas en general y, en 
particular, un impuesto a los servicios digitales que afecte a los grandes medios capitalistas transnacionales y a las empresas digitales.

6. La democracia digital, la esfera pública digital y los comunes digitales necesitan espacio, tiempo, apoyo material y asociaciones entre el público y la sociedad civil. El soporte material ayuda a crear ese espacio y tiempo. Los impuestos corporativos y una tarifa de medios pagada no sólo por los ciudadanos, sino también por las empresas, pueden crear un apoyo material para proyectos alternativos. La tarifa de la licencia debe mantenerse donde exista e introducirse donde aún no existe y ser utilizada para financiar proyectos de servicios públicos de Internet y medios de comunicación de servicio público. La tarifa de la licencia debe extenderse de los hogares a las corporaciones y pasar de una tarifa plana a una tarifa progresiva. El presupuesto participativo se puede combinar con los impuestos corporativos de manera de crear un cheque de la esfera pública que los ciudadanos reciban para apoyar proyectos alternativos, democráticos de la esfera pública y de la sociedad civil. En lugar de asociaciones público-privadas, se necesitan asociaciones entre lo público y la sociedad civil donde las organizaciones públicas cooperen con organizaciones de la sociedad civil. Donde sea posible y factible, debería haber asociaciones de proyectos de Internet de servicio público y proyectos de Internet de la sociedad civil. Apelando a tales formas de apoyo material, los proyectos de Internet de servicio público y los proyectos de Internet de la sociedad civil, y las redes de servicio público y las organizaciones de la sociedad civil deberían crear plataformas de Internet de, para y a través de la esfera pública que promuevan los comunes digitales y sigan el mandato de promover la democracia, la educación, la cultura y la participación en la sociedad con la ayuda de las tecnologías digitales. Tales plataformas de Internet públicas, civiles y público/civiles desafían a las plataformas de Internet capitalistas y, por lo tanto, al capitalismo digital.

7. Habilidades digitales, críticas y democráticas: La democracia digital requiere ciudadanos críticos y comprometidos que practiquen el debate democrático y la democracia. Los ciudadanos requieren tiempo, espacios, oportunidades educativas y oportunidades de participación de manera de desarrollar y practicar habilidades democráticas, digitales, políticas, sociales, culturales y otras. Por un lado, la participación y el compromiso con los demás es educación sobre la participación. Por otro lado, medidas como la reducción de la jornada laboral con compensación salarial completa, la introducción de un ingreso básico redistributivo financiado con impuestos al capital, la educación política y digital en las escuelas y una ofensiva en el aprendizaje de adultos basada en los principios de la pedagogía crítica, etcétera, son medidas materiales que proporcionan bases y apoyo para el desarrollo de habilidades. La política digital progresista debería promover oportunidades educativas críticas.

8. Desaceleración, medios lentos: la esfera pública necesita tiempo para el pensamiento crítico, la lectura, la redacción crítica, la presentación crítica, el debate crítico, la coproducción crítica. Los medios digitales pueden respaldar esos procesos que vinculan las prácticas online y las prácticas cara a cara. Las plataformas digitales deben diseñarse de tal manera que permitan a los humanos dedicar el tiempo suficiente a las habilidades críticas recién mencionadas.

9. Privacidad y minimización de datos: Los medios digitales no capitalistas deberían respetar la privacidad de ciudadanos, trabajadores y consumidores. Deben utilizar el principio de privacidad por diseño, minimizar el almacenamiento de datos a aquellos necesarios para la operación de las plataformas y estar libres de publicidad.

10. Las plataformas de Internet de servicio público y las plataformas de Internet de la sociedad civil, así como sus usuarios, deben respetar y promover la democracia, la pluralidad de opiniones que respeta los derechos humanos y la igualdad de todos los seres 
humanos, el anti-clasismo, el anti-racismo, la igualdad de género, el anti-fascismo y la inclusión. Promover la participación no debe ser una excusa para habilitar el fascismo, el racismo y otros discursos de odio. Las noticias y los programas educativos requieren altos estándares de calidad y siempre deben ser veraces. No hay lugar para noticias falsas y políticas de posverdad en los medios progresistas. Aquellos que sostienen opiniones discriminatorias deben poder hablar siempre y cuando no infrinjan las leyes (por ejemplo, al expresar amenazas de muerte o amenazas violentas), pero sus opiniones siempre deben ser adecuadamente discutidas.

Hoy, la sociedad digital es un capitalismo digital que socava la democracia, la esfera pública y el bien común. Las políticas digitales progresistas que promueven la esfera pública digital y los comunes digitales junto con la esfera pública, los servicios públicos y lo común en general son la esperanza activa y práctica para salvaguardar y promover la democracia en la era de, y en oposición a, el autoritarismo digital.

\section{Referencias}

Bauwens, M., Kostakis, V., \& Pazaitis, A. (2019). Peer to Peer: The Commons Manifesto. London: University of Westminster Press. DOI: https://doi.org/10.16997/book33

Benkler, Y. (2006). The Wealth of Networks: How Social Production Transforms Markets and Freedom. New Haven, CT: Yale University Press.

Benkler, Y. (2013). Commons and growth: The essential role of open commons in market economies. University of Chicago Law Review, 80, 1499-555.

Berlinguer, M. (2020). New commons: Towards a necessary reappraisal. Popular Communication, 18(3), 201-15. DOI: https://doi.org/10.1080/15405702.2020.1781857

Birkinbine, B. J. (2020). Incorporating the Digital Commons: Corporate Involvement in Free and Open Source Software. London: University of Westminster Press. DOI: https://doi.org/10.16997/book39

Broumas, A. (2020). Intellectual Commons and the Law: A Normative Theory for CommonsBased Peer Production. London: University of Westminster Press. DOI: https://doi.org/10.16997/book49

Cody, S. (2008). After Kelly: 'After Dark', David Kelly and lessons learned. Lobster, 55.

Der Standard. (2001). Der 'Club 2' ging vor 25 Jahren erstmals auf Sendung. Der Standard Online, 5 October. Available at: www.derstandard.at/story/733146/der-club-2-ging-vor-25jahren-erstmals-auf-sendung (last accessed 7 October 2020).

Euler, J. (2018). Conceptualizing the commons: Moving beyond the goods-based definition by introducing the social practices of commoning as vital determinant. Ecological Economics, 143, 10-16. DOI: https://doi.org/10.1016/j.ecolecon.2017.06.020

Fuchs, C. (2014a). Digital prosumption labour on social media in the context of the capitalist regime of time. Time \& Society, 23(1), 97-123. DOI: https://doi.org/10.1177/0961463X13502117

Fuchs, C. (2014b). Social media and the public sphere. tripleC: Communication, Capitalism \& Critique, 12(1), 57-101. DOI: https://doi.org/10.31269/triplec.v12i1.552

Fuchs, C. (2018a). Digital Demagogue: Authoritarian Capitalism in the Age of Trump and Twitter. London: Pluto. DOI: https://doi.org/10.2307/j.ctt21215dw 
Fuchs, C. (2018b). The Online Advertising Tax as the Foundation of a Public Service Internet. London: University of Westminster Press. DOI: https://doi.org/10.16997/book23

Fuchs, C. (2020a). Communication and Capitalism: A Critical Theory. London: University of Westminster Press. DOI: https://doi.org/10.16997/book45

Fuchs, C. (2020b). Nationalism on the Internet: Critical Theory and Ideology in the Age of Social Media and Fake News. New York: Routledge. DOI: https://doi.org/10.4324/9780429343476

Fuchs, C. (2021). Social Media: A Critical Introduction, 3rd edition. London: Sage.

Fuchs, C., \& Sandoval, M. (2013). The diamond model of open access publishing: Why policy makers, scholars, universities, libraries, labour unions and the publishing world need to take non-commercial, non-profit open access serious. tripleC, 11(2): 428-43. DOI: https:// doi.org/10.31269/triplec.v11i2.502

Habermas, J. (1989). The Structural Transformation of the Public Sphere. Cambridge, MA: MIT Press.

Hardt, M., \& Negri, A. (2017). Assembly. Oxford: Oxford University Press.

Harvey, D. (2005). A Brief History of Neoliberalism. Oxford: Oxford University Press. DOI: https://doi.org/10.1093/oso/9780199283262.001.0001

Held, D. (2006). Models of Democracy. Cambridge: Polity.

Hess, C., \& Ostrom, E. (2007). Understanding Knowledge as Commons: From Theory to Practice. Cambridge, MA MIT Press. https://doi.org/10.7551/mitpress/6980.001.0001

Knoche, M. (2020). Science communication and open access: The critique of the political economy of capitalist academic publishers as ideology critique. tripleC: Communication, Capitalism \& Critique, 18(2): 508-34. DOI: https://doi.org/10.31269/triplec.v18i2.1183

Kohler, B., David, S., \& Blumtritt, J. (2010). The slow media manifesto. Available at: http:// en.slow-media.net/manifesto (last accessed 2 November 2019).

Marx, K. (1867) [1990]. Capital. Volume 1. London: Penguin.

Marx, K. (1894) [1992]. Capital. Volume 3. London: Penguin.

Marx, K., \& Engels, F. (1848) [1976]. Manifesto of the Communist Party. In Marx and Engels Collected Works (MECW) Volume 6 (pp. 477-519). London: Lawrence and Wishart.

Papadimitropoulos, V. (2020). The Commons: Economic Alternatives in the Digital Age. London: University of Westminster Press. DOI: https://doi.org/10.16997/book46

Rauch, J. (2018). Slow Media. Why Slow' is Satisfying, Sustainable, and Smart. Oxford: Oxford University Press.

Rosa, H. (2013). Social Acceleration: A New Theory of Modernity. New York: Columbia University Press. DOI: https://doi.org/10.7312/rosa14834

Sandoval, M. (2020). Entrepreneurial activism? Platform co-operativism between subversion and co-optation. Critical Sociology, 46(6), 801-17. DOI: https://doi.org/10.1177/0896920519870577

Scholz, T. (2016). Platform Cooperativism: Challenging the Corporate Sharing Economy. New York: Rosa Luxemburg Stiftung.

Scholz, T. (2017). Uberworked and Underpaid: How Workers Are Disrupting the Digital Economy. Cambridge: Polity Press. 
Scholz, T., \& Schneider, N. (Eds.) (2016). Ours to Hack and to Own: The Rise of Platform Cooperativism, a New Vision for the Future of Work and a Fairer Internet. New York: OR Books. DOI: https://doi.org/10.2307/j.ctv62hfq7

Splichal, S. (2007). Does History Matter? Grasping the Idea of Public Service at its Roots In G. F. Lowe \& J. Badoel (Eds.), From Public Service Broadcasting to Public Service Media, RIPE@2007 (pp. 237-56). Gothenburg: Nordicom.

Srnicek, N. (2017). Platform Capitalism. Cambridge: Polity Press.

Utman, J. S. (2020). Subversive communication against neoliberalism. Popular Communication, 18(3), 155-69. DOI: https://doi.org/10.1080/15405702.2020.1781858

Zižek, S. (2010). How to Begin From the Beginning. In C. Douzinas \& S. Žižek (Eds.), The Idea of Communism (pp. 209-26). London: Verso. 